\title{
Incidence of venous thromboembolism verified by necropsy over 30 years
}

\author{
B Lindblad, N H Sternby, D Bergqvist
}

\begin{abstract}
Objective-To determine the incidence of venous thromboembolism in all necropsy reports over $\mathbf{3 0}$ years.

Design-Study of all necropsies in one hospital in 1987 and longitudinal analysis of results of necropsy in $1957,1964,1975$, and 1987.
\end{abstract}

Setting-Departments of general surgery, infectious diseases, internal medicine, oncology, and orthopaedics in a Swedish general hospital.

Main outcome measure-Number of cases of venous thromboembolism.

Results-About a third of all necropsies showed venous thromboembolism. In 1987, 260 of 347 necropsies showing venous thromboembolism found pulmonary embolism, of which 93 were classified as fatal, 90 as contributory, and 77 as incidental. Only 21 contributory or fatal postoperative pulmonary emboli were seen. In only 106 of 260 patients with pulmonary embolism did routine necropsy not show the source of embolism. Calf veins were not routinely examined. Deep venous thrombosis was seen in 239 patients in 1987. The incidence of venous thromboembolism in the four years studied was remarkably stable except in the department of orthopaedics, where the proportion fell from $60.7 \%$ in 1975 to $32.2 \%$ in $1987(p<0 \cdot 05)$, although there were only a few patients.

Conclusions-The overall incidence of venous thromboembolism has not changed over 30 years. During this period the proportion of the population aged over 65 has doubled, and this may have masked the beneficial effects of prophylaxis and early mobilisation. Prevalences corrected for age are needed.

\section{Introduction}

Venous thromboembolism is an important cause of death. Patients are now mobilised soon after surgery, myocardial infarction, or cerebrovascular accident routinely. In addition, the increasing use of prophylaxis for thromboembolism in patients undergoing surgery as well as advances in anaesthesia and intensive care ought to reduce the incidence of the condition. It is not known, however, whether these changes have reduced the number of cases of thromboembolism. More elderly patients undergo more extensive procedures such as reconstructive surgery (hip and knee replacement, peripheral vascular surgery) or operations for cancer, and increased incidence of thromboembolism in these patients may counteract the expected beneficial effects. We studied the pattern of serious venous thromboembolism within a population over 30 years.

Malmö has 230000 inhabitants and is served by one hospital, to which all patients are referred. A high rate of necropsy and the fact that the protocol for necropsy has been the same over the past 30 years improve the validity of this analysis.

\section{Material and methods}

We reviewed all necropsy reports and selected those with findings of venous thromboembolism for further analysis. Routine postmortem examination included exposure of thigh vessels to the level of the adductor canal and exposure of the subclavian veins. The pulmonary artery tree was dissected at least to segmental level and the lung was examined histologically.

Based on data from the necropsy report, the death certificate, and the patient's records, the pulmonary emboli were classified into three categories: fatal pulmonary emboli (no other causes of death found at necropsy, emboli occluding at least two lobar arteries); contributory pulmonary emboli (factors other than pulmonary emboli implicated, emboli occluding at least one lobar artery or multiple segmental arteries); and incidental pulmonary emboli (small or old pulmonary emboli, macroscopic or microscopic, not considered to be related to death).

\begin{tabular}{cccccc}
\multicolumn{2}{c}{ TABLE I-Epidemiological data for Malmö for four years studied } \\
\hline \multicolumn{1}{c}{$\begin{array}{c}\text { No (\%) } \\
\text { Year }\end{array}$} & $\begin{array}{c}\text { Population } \\
\text { aged over 65 }\end{array}$ & $\begin{array}{c}\text { No of } \\
\text { deaths }\end{array}$ & $\begin{array}{c}\text { No dying in } \\
\text { analysed } \\
\text { departments* }\end{array}$ & $\begin{array}{c}\text { \% With } \\
\text { necropsy }\end{array}$ \\
\hline 1957 & 217330 & $23214(10 \cdot 7)$ & 1854 & 782 & $98 \cdot 0$ \\
1964 & 245803 & $28557(11 \cdot 6)$ & 2202 & 1134 & $98 \cdot 5$ \\
1975 & 243591 & $39700(16 \cdot 3)$ & 2749 & 1469 & $96 \cdot 1$ \\
1987 & 230838 & $49232(21 \cdot 3)$ & 2981 & 1293 & $76 \cdot 9$ \\
\hline
\end{tabular}

${ }^{\star}$ Departments analysed were general surgery, infectious diseases, internal medicine, oncology, and orthopaedics.

We looked at all necropsies from the departments of general surgery, infectious diseases, internal medicine, oncology, and orthopaedics. Table I gives the numbers of inhabitants and hospital deaths in the investigated departments and the necropsy rates are for the years studied. Statistical analysis was by the $\chi^{2}$ test; $p$ values less than 0.05 were considered significant.

\section{Results}

In 1987, 1293 people died in the hospital departments studied and $994(76.9 \%)$ were examined at necropsy; venous thromboembolism was found in 345 . Table II gives descriptive data on these patients. In 154 cases a combination of pulmonary embolism and deep venous thrombosis was found, in 106 pulmonary embolism was found without venous thrombosis, and in 85 deep venous thrombosis was detected without pulmonary embolism. Thrombi occurred on the left and right side equally often, and in 81 cases were bilateral. Thrombi were detected in the veins of the upper extremity in 19 cases and in the superior caval vein in eight. Most thrombi in the inferior vena cava (11 of 13 cases) were 


\begin{tabular}{|c|c|c|c|c|c|c|c|}
\hline \multirow[b]{2}{*}{ Department } & \multirow{2}{*}{$\begin{array}{l}\text { No of patients } \\
\text { admitted } \\
\text { to hospital }\end{array}$} & \multirow[b]{2}{*}{$\begin{array}{l}\text { No of } \\
\text { deaths }\end{array}$} & \multirow{2}{*}{$\begin{array}{c}\text { No }(\%) \\
\text { with } \\
\text { necropsy }\end{array}$} & \multicolumn{4}{|c|}{ Results of necropsy (No of cases) } \\
\hline & & & & $\begin{array}{c}\text { Venous } \\
\text { thromboembolism }\end{array}$ & $\begin{array}{l}\text { Deep venous } \\
\text { thrombosis }\end{array}$ & $\begin{array}{l}\text { Pulmonary } \\
\text { embolism }\end{array}$ & $\begin{array}{c}\text { Fatal pulmonary } \\
\text { embolism }\end{array}$ \\
\hline General surgery & 9209 & 246 & $197(80)$ & 79 & 56 & 66 & 20 \\
\hline Infectious diseases & 2220 & 120 & $101(84)$ & 27 & 20 & 22 & 8 \\
\hline Internal medicine & 9956 & 639 & $482(76)$ & 170 & 113 & 123 & 44 \\
\hline Oncology & 1279 & 204 & $754(76)$ & 50 & 39 & 33 & 11 \\
\hline Orthopaedics & 3434 & 84 & $59 \cdot(70)$ & 21 & 11 & 16 & 10 \\
\hline Total & 26078 & 1293 & $994(77)$ & 347 & 239 & 260 & 93 \\
\hline
\end{tabular}

seen in surgical patients. There were 26 cases of cardiac thrombi.

Table III shows the longitudinal analysis of the incidence of venous thromboembolism in 1957, 1964 , 1975, and 1987. Venous thromboembolism continues to be a common finding at necropsy, but the number of cases occurring in patients in the department of orthopaedics fell significantly in $1987(p<0.05)$. This represents a small reduction in the number of patients with pulmonary embolism and a somewhat larger reduction in the number with deep venous thrombosis diagnosed at necropsy. For the other departments the figures are remarkably stable during the analysed period.

Of the 260 cases of pulmonary emboli, 77 were incidental (35 of these microscopic), 93 fatal, and 90 contributory. Of the contributory and fatal emboli, only 21 occurred postoperatively ( 10 in general surgical patients and 11 in orthopaedic patients). All but one of these 21 patients had received prophylaxis. The postoperative emboli occurred on the 13th day (median, range 1 to 30 days) after surgery. Lung infarction was seen in 92 cases, in 90 in conjunction with contributory or fatal pulmonary embolism. In patients with pulmonary embolism no finding of deep venous thrombosis was noted in $40 \%$ (106) of the necropsies, but the routine necropsy did not include the crural vessels. Table IV shows the incidences of venous thromboembolism and pulmonary embolism related to the numbers of necropsies and patients in hospital.

\section{Discussion}

Our study verifies the continuing threat of venous thromboembolism to patients admitted to hospital and the frequent finding of venous thromboembolism at necropsy. In 1987 about a third of necropsies showed

TABLE III - Percentage of necropsies in which venous thromboembolism (fatal pulmonary embolism) was found, by year and hospital department

\begin{tabular}{lccccc}
\hline Year & $\begin{array}{c}\text { General } \\
\text { surgery }\end{array}$ & $\begin{array}{c}\text { Infectious } \\
\text { diseases }\end{array}$ & $\begin{array}{c}\text { Internal } \\
\text { medicine }\end{array}$ & Oncology & Orthopaedics \\
\hline $1957^{\prime}$ & $40 \cdot 8(9 \cdot 2)$ & $35 \cdot 3(10 \cdot 9)$ & $26 \cdot 6(8 \cdot 0)$ & & $57 \cdot 7(11 \cdot 5)$ \\
$1964^{\star}$ & $31 \cdot 5(9 \cdot 0)$ & $26 \cdot 8(6 \cdot 1)$ & $26 \cdot 1(8 \cdot 0)$ & $34 \cdot 4(6 \cdot 3)$ & $59 \cdot 2(16 \cdot 2)$ \\
$1975 \dagger$ & $42 \cdot 1(4 \cdot 6)$ & $30 \cdot 8(4 \cdot 1)$ & $28 \cdot 7(5 \cdot 9)$ & $44 \cdot 9(5 \cdot 6)$ & $60 \cdot 7(25 \cdot 0)$ \\
$1987^{\circ}$ & $39 \cdot 7(10 \cdot 1)$ & $26 \cdot 7(7 \cdot 9)$ & $35 \cdot 3(9 \cdot 1)$ & $32 \cdot 5(7 \cdot 1)$ & $32 \cdot 2(16 \cdot 9)$ \\
\hline
\end{tabular}

ॠ H Braconier, unpublished observations.

tS Johansson, unpublished observations.

TABLE IV - Incidence of venous thromboembolism in Malmö General Hospital

\begin{tabular}{|c|c|c|c|c|c|}
\hline \multirow[b]{2}{*}{ Year } & \multicolumn{3}{|c|}{$\%$ Of necropsies finding: } & \multicolumn{2}{|c|}{$\begin{array}{l}\% \text { Of hospital patients found a } \\
\text { necropsy to have had: }\end{array}$} \\
\hline & $\begin{array}{c}\text { Venous } \\
\text { thromboembolism }\end{array}$ & $\begin{array}{l}\text { Pulmonary } \\
\text { embolism }\end{array}$ & $\begin{array}{c}\text { Fatal } \\
\text { pulmonary } \\
\text { embolism }\end{array}$ & $\begin{array}{l}\text { Pulmonary } \\
\text { embolism }\end{array}$ & $\begin{array}{c}\text { Fatal } \\
\text { pulmonary } \\
\text { embolism }\end{array}$ \\
\hline $1957^{\prime}$ & $34 \cdot 3$ & $21 \cdot 0$ & 8.9 & $1 \cdot 12$ & 0.48 \\
\hline $1964^{\star}$ & $31 \cdot 3$ & $22 \cdot 4$ & $8 \cdot 3$ & 1.51 & 0.56 \\
\hline $1975 \dagger$ & $35 \cdot 1$ & 24.4 & 5.9 & 1.39 & 0.32 \\
\hline 1987 & $34 \cdot 7$ & $26 \cdot 1$ & $9 \cdot 4$ & 0.99 & $0 \cdot 36$ \\
\hline
\end{tabular}

${ }^{\star} \mathrm{J} \mathrm{H}$ Braconier, unpublished observations.

†S Johansson, unpublished observations. venous thromboembolism, a similar proportion to that found in 1957,' 1964, and 1975. The proportion of cases was less than that found by necropsies specially designed to investigate thoroughly venous thromboembolism. ${ }^{2}{ }^{3}$ Nevertheless, the likelihood that relevant venous thromboembolism was not found at our routine examination is minimal, as is the risk of misclassification of clots formed after death as thrombi or emboli because microscopy was used to verify the diagnosis if it was doubtful. The analysis also suffers from a fall in necropsy rate in 1987 to $77 \%$. The reduced rate is still high but represents a possibility for errors where, for example, patients with fatal malignancies that are associated with higher rate of venous thromboembolism do not have necropsies.

The high and unaltered incidence of venous thromboembolism found despite the progress in medicine and the more common use of prophylaxis could be due to many factors. Malmö has undergone major changes during the past 30 years. A larger proportion of the population in 1987 were older than 65 (table I) than in other years, but as the age distribution of previous series is not known corrections for changes in age cannot be established. In a survey of pulmonary embolism in surgical patients a clear change was seen in the age distribution with more elderly patients presenting in the past two decades. ${ }^{4} \mathrm{We}$ found, however, that the incidence of venous thromboembolism was unchanged, which suggests that the age corrected incidence might be reduced. Only a few of the patients with postoperative venous thromboembolism in 1987 had had elective procedures. In these patients venous thromboembolism was seen later than in other patients and often after a prolonged and complicated postoperative course.

The reduction in the incidence of venous thromboembolism in the department of orthopaedics must be evaluated cautiously as the number of patients with venous thromboembolism in this department was small. Additionally, the reduction could be explained by more patients with hip fractures being transferred soon after their operations to other types of rehabilitation units. Nevertheless, not one single case of fatal or contributory pulmonary embolism was seen after reconstructive elective orthopaedic surgery. This has probably been achieved because of a frequent use of prophylaxis.

The diagnosis of a thrombus or an embolus and its classification is partly subjective, but the unaltered technique for necropsy and almost the same senior staff at the department of clinical pathology during the 30 years makes our classification reasonably valid. The increasing efforts to reduce venous thromboembolism by early mobilisation and pharmacological prophylaxis have not reduced the total incidence of venous thromboembolism verified at necropsy. Corrections for alterations in the age structure of the population and the more aggressive treatment in higher age groups, however, have not been considered. In part, these factors could explain the unaltered incidence of venous thromboembolism. To be able to continue to make epidemiological analyses of changes in diseases 
such as pulmonary embolism it is necessary that at least some centres continue to have a high necropsy rate.

This work was supported by the Swedish Medical Research Council (grant number 00759).

1 Kaij K. Tromboembolifrekvensen i ett obduktionsmaterial. Lakartidningen 1959;56:1437-43.
2 Havig 0 . Deep vein thrombosis and pulmonary embolism. An autopsy study with multiple regression analysis of possible risk factors. Acta Chir Scand 1977; Suppl 478:1-92.

3 Rubinstein I, Murray D, Hoffstein V. Fatal pulmonary emboli in hospitalized patients. An autopsy study. Arch Intern Med 1988;148:1425-6.

4 Bergqvist D, Lindblad B. A 30-year survey of pulmonary embolism verified at autopsy: an analysis of 1274 surgical patients. Br $\mathcal{f}$ Surg 1985;72:105-8.
British Medical Journal, London WC1H 9JR

Richard Smith, MB, executive editor

BMF 1991;302:711-4

\title{
William Waldegrave: thinking beyond the new NHS
}

\author{
Richard Smith
}

RS: Doctors and managers in London are particularly depressed about the NHS changes. Mightn't the changes spell disaster for London because of the high costs and the highly complicated cross boundary flows? ww: London seems to me to be an extreme case of how the present system doesn't work. We've got nearly a third of the beds in London closed and yet we have long waiting lists and difficult access to beds - in some parts at least. People are working under great strain and are unhappy - and I don't blame them for being so.

What the new system will do will force some decisions out of us cowardly politicians, who for 20 years have put them off. The new system will begin to bring things to a sharp crunch in a number of places. I'm not one of those who thinks that everybody knows what to do and it's just a matter of doing it. I don't know whether it's a matter of taking out one teaching hospital or whatever: I simply don't know that. What I do know is that after we have watched the flows of money becoming more explicit we will begin to get some much clearer indications about what to do.

I don't think that it is inevitable that the famous and relatively expensive hospitals will lose out. Americans will travel to famous hospitals: why shouldn't the British? What is clear is that it must be crazy to run al the hospitals in London below capacity so that none of them are working efficiently but are all semidemoralised. It must be very depressing to work with large numbers of beds closed. In economic, morale, and organisational terms this is a poor state of affairs, and we can't let that drag on.

“...It must be very depressing to work with large numbers of beds closed. In economic, morale, and organisational terms this is a poor state of affairs, and we can't let that drag on."

The new system will bring it to a head, and whoever has to make those difficult decisions will be extremely unpopular for a time-and will be like the man who amalgamated the regiments of the British army. The equivalents of mad Mitch will be after him like nobody's business. But if he gets it right he will have helped the whole system in England.

RS: Your argument is that he or she will have the information necessary to make that decision?

ww: Yes. Firstly, he or she will be forced to take the decision, and, secondly, he or she will have much more information to make the right decision.
RS: How long is that going to take?

ww: I think that the next couple of years will bring this to a head.

RS: So it could be you having to take these decisions?

ww: I hope that it is. It would be wonderful to be involved in getting a rational health service in London. RS: Are you confident that research and teaching are going to survive this onslaught?

ww: They must, that's a given. If things go wrongwhich I don't think they will - then they will just have to be looked after. What I do say is, I don't think that it's right that the teaching tail should wag the whole dog. We should be able to organise teaching in terms of what we need for health provision for patients. The disposition of teaching facilities should not be allowed to distort the health provision.

\section{Community care}

RS: Let's talk a little about community care, which has been rather forgotten in all the fuss surrounding the new NHS. Shouldn't you move it forward again?

ww: My preference would be to move it forward, but I don't think that it's practical. It would get caught up in the reforms of local government, which are still ongoing. Equally, however, I think that I can guarantee that it's not going to slip any furtherwhatever the structures of local government. And the Prime Minister has reaffirmed this recently. We will put the leadership with the local authority side. My job is to make sure that from the health service side the web is seamless.

And there are some benefits to set against the delay: people will be better trained and will understand better what is expected of them. I actually find some of the most exciting papers on my desk those that are to do with greater integration of primary and secondary care and of community health with social services. There's real room for exciting developments there.

RS: So is that something you might make a priority for the future?

ww: Exactly.

\section{Preventive care}

RS: Preventive care is something else that seems to have been rather forgotten recently. Are you, for instance, doing enough about tobacco? Doctors who have been watching this for 30 years can't understand why you don't bump up the price dramatically or ban advertising.

ww: Price is the main thing, and that is a matter for the Chancellor. I've made it clear to him what we want, but 